\title{
Business Strategy and Innovativeness: Results from an Empirical Study
}

\author{
Gündüz Ulusoy ${ }^{1}$, Gürhan Günday ${ }^{1}$, Kemal Kılıç ${ }^{1}$, and Lütfihak Alpkan ${ }^{2}$ \\ ${ }^{1}$ Faculty of Engineering and Natural Sciences, Sabanci University, \\ Istanbul, Turkey \\ \{gunduz, ggunday, kilic\} @sabanciuniv.edu \\ ${ }^{2}$ Faculty of Management, Gebze Institute of Technology, Kocaeli, Turkey \\ alpkan@gyte.edu.tr
}

\begin{abstract}
This study reports on the testing of the hypothesis that there is a positive relationship between business strategy and innovativeness. Business strategy is defined here to include market focus strategy, technology development strategy, and operations priorities - including cost, quality, delivery / dependability, and flexibility. An empirical study is conducted based on data collected using a questionnaire developed. 184 manufacturing firms from different industries in the Northern Marmara region in Turkey participated in the study. Multivariate statistics techniques and structural equation modeling are employed. The results have been affirmative supporting the hypothesis. Market focus and technology development factors are found to mediate the effects of operations priorities on innovativeness. That market focus, technology development and cost efficiency have direct effects on innovativeness is another finding of managerial importance.
\end{abstract}

Keywords: Business strategy, innovativeness, empirical study, structural equation modeling.

\section{Introduction}

This study aims to test the hypothesis that there is a positive relationship between business strategy and innovativeness. Business strategy is defined here to include market focus strategy, technology development strategy, and operations priorities also called manufacturing capabilities in the literature- including cost, quality, delivery/dependability, and flexibility (see e.g., Hayes and Wheelwright, 1984; Leong et al., 1990). The foremost aim of firms is to survive in the market while generating profit. In the highly dynamic market conditions of today, firms are under the pressure of strong competition in order to gain competitive advantage and to upgrade the efficiency of work and innovation provides them with an effective tool for that purpose, since innovations are among the essential resources through which firms contribute to increased employment, economic growth, and competitive strength. The purpose of innovation is to launch newness into the economic area. As stated by Metcalfe (1998), when the flow of newness and innovations desiccate, the firm's economic structure settles down in an inactive state with little growth. 
Four different innovation types are employed in this research: product, process, marketing and organizational innovations (OECD, 2005). We define here innovativeness to embody some kind of measurement contingent on an organization's proclivity towards innovation (Salavou, 2004).

\section{Data Collection and Measurement of Variables}

\subsection{Data Collection}

A questionnaire consisting of 311 individual questions was developed to be filled in by the upper managers of manufacturing companies. The questionnaire was updated based on the experience gained through a pilot test phase covering 10 firms. Afterwards data was collected over a 7-month period in 2006-2007 in textile, chemical, metal products, machinery, domestic appliances and automotive industries in the Northern Marmara region of Turkey. These industries were selected to represent the major manufacturing sectors in Turkey. A manufacturing business unit was selected as the unit of analysis. A total of 184 usable questionnaires were obtained resulting in a response rate of $11 \%$. All the respondents completing the questionnaire were from the top $(52 \%)$ or middle management $(48 \%)$. For each sector, number of firms in the sample turned out to be representative, since no significant difference has been detected between the population and the sample percentages.

The profile of the resulting sample presented in Figure 1 illustrates its diversity in terms of firm characteristics. Firm size is determined by the number of full-time employees (up to 50: small, 50 $\leq$ medium $<250$, $\geq 250$ : large). In addition to the number of full-time employees, for a firm to be classified as large it is required to have an annual revenue $\geq 50 \mathrm{M} €$. For small and medium firms, four annual revenue brackets are defined so as to have a balance between small and medium firms. Firm age is determined by the year production had started (up to 1975: old; $1975 \leq$ moderate $<1992 ; \geq 1992$ : young). Joint stock companies constitute $73 \%$ of the sample with the remaining being limited companies. $19 \%$ of the firms in the sample have some level of foreign direct investment.

\subsection{Measurement of Variables}

As we will see in the following, the questions for measurement purpose are asked using a 5-point Likert scale. Such subjective measures possibly bring in manager bias, but are widespread practice in empirical researches (Khazanchi et al., 2007).

First we will deal with the questions concerning the business strategy constructs. The variables of market focus are given in Table 1. A 5-point Likert scale is employed to assess how important each one has been for the firm in the last three years with a scale ranging from $1=$ extremely unimportant to $5=$ extremely important. 


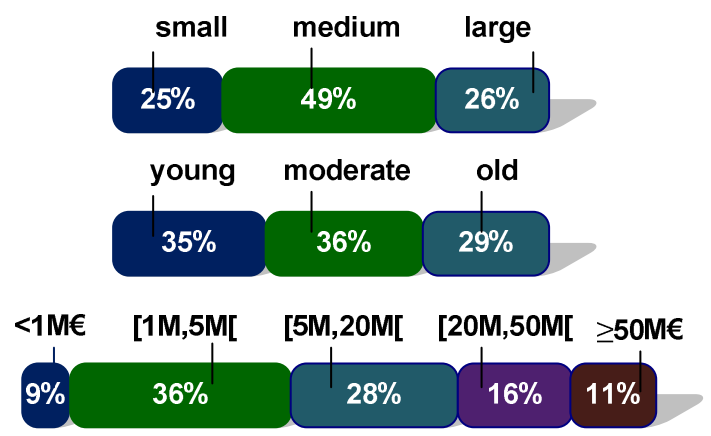

Fig. 1. Sample profile

Table 1. Variables Associated with Market Focus Strategy

\begin{tabular}{ll}
\hline 1 & Making incremental changes in current products for current markets. \\
2 & Developing new products for current products. \\
3 & Entering new markets with current products. \\
4 & Entering new markets with new products. \\
\hline
\end{tabular}

Table 2. Variables Associated with Technology Development Strategy

1 Developing new technology.

2 Improving its own technology.

3 Improving technology developed by others.

$4 \quad$ Using technology developed by others.

For technology development strategy, on the other hand, for responding to the question on "the level of resource allocated to execute technology development strategy over the last three years" the 5-point Likert scale employed ranges from $1=$ no resource allocated to $5=$ all available resources are allocated. The variables are listed in Table 2. For both market focus and technology development the variables are adapted from Akova et al. (1998).

The questions about operations priorities are provided in Table 3. They are asked using a 5-point Likert scale and inquiring how important each operations priority is for the firm with the scale ranging from $1=$ extremely unimportant to $5=$ extremely important. Here we adopt cost, quality, flexibility and delivery/dependability as operations priorities, which have become widely used as statements of the competitive dimensions of manufacturing firms. The variables of the four different operations priorities' measures are adapted from existing OM literature. The base of items asked regarding these operations priorities are adapted mainly from Boyer and Lewis (2002), Alpkan et al. (2003), Noble (1997), Ward et al. (1998), Vickery et al. (1993), Kathuria (2000) and Olson et al. (2005). 
Innovation constructs are associated with those four different innovation types mentioned earlier. Each innovation construct is measured by its original measurement items, which are developed accordingly. Therefore, innovation measures used in this research are new for the literature and hence have been validated.

Table 3. Variables Associated with Operations Priorities

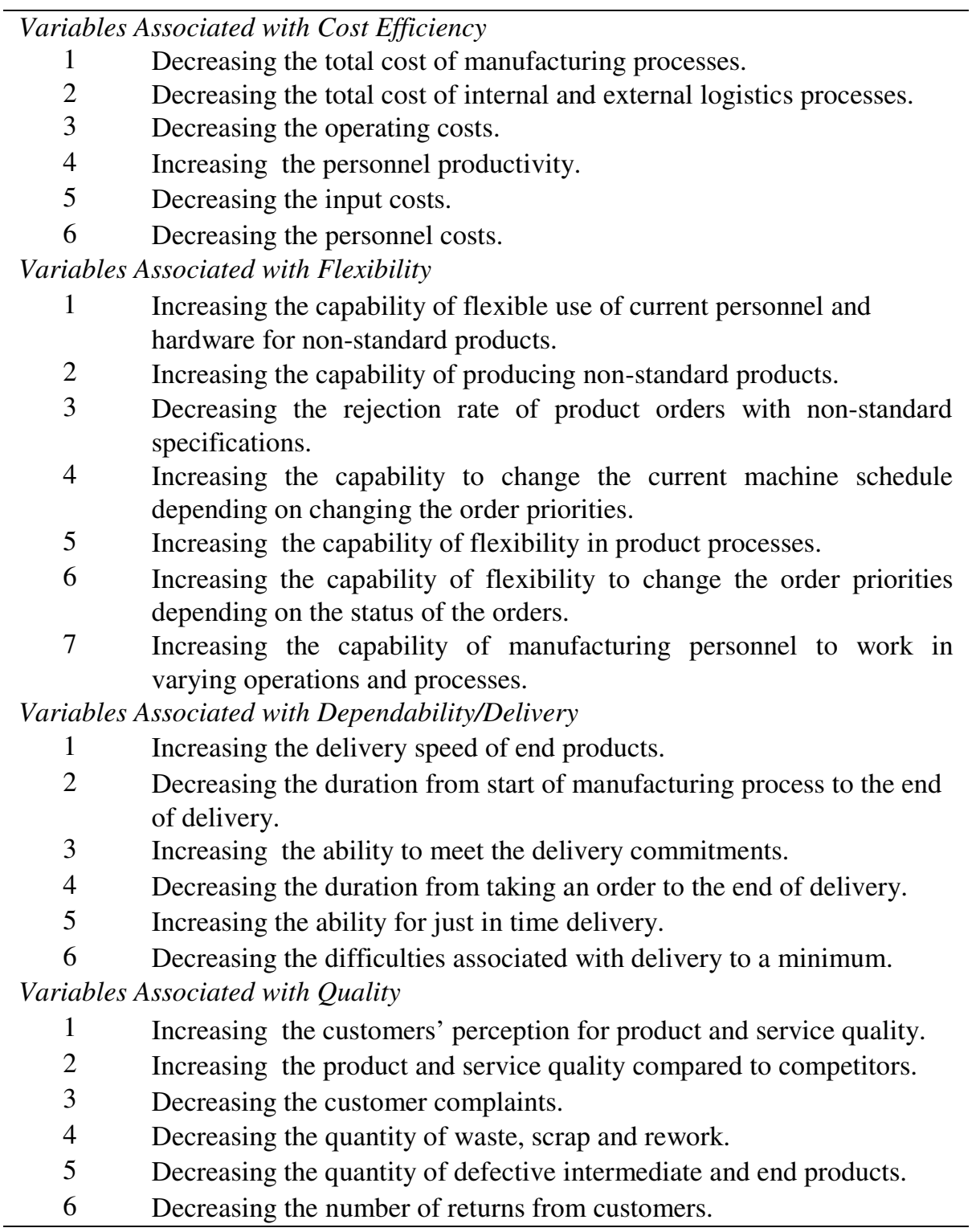


For the measurement of different types of innovative capabilities the respondents are asked to indicate "to what extent the innovations implemented in their organization in the last three years related to the following kinds of activities" on a 5-point Likert scale ranging from $1=$ not implemented, $2=$ imitated from national markets, $3=$ imitated from international markets, $4=$ currently practiced endogenous innovations are improved, $5=$ original indigenous innovations are implemented. Due to space limitation we will refer the reader to Günday et al. (2011) for a complete list of variables used for the measurement of product, process, market and organizational innovations.

\section{$3 \quad$ Analysis and Results}

The multivariate data analysis is performed in three stages using statistical software packages SPSS v17 and AMOS v16.

In the first stage, principal component analysis (PCA) with varimax rotation is conducted to find out the underlying dimensions of business strategy items and innovativeness. PCA on business strategy items produced 6 factors with latent root criterion and the average of communalities was 0.551. All the variables given in Tables 1-3 are included in the factors. The six factors obtained are assigned the following titles: quality, flexibility, delivery and dependability, cost efficiency, market focus, and technology development strategies. The total variance explained is $55.1 \%$. The Cronbach $\alpha$ values are $\geq 0.62$ suggesting construct reliability.

The PCA on innovativeness extracted 5 factors with eigenvalues $>1$, which are labeled based on the variables involved: Organizational, marketing, process, incremental product, and radical product innovations. The total variance explained is $63.7 \%$. The Cronbach $\alpha$ values are $\geq 0.7$ suggesting construct reliability. Then we construct an aggregate innovativeness factor as the average of five innovation factors obtained with a Cronbach $\alpha=0.812$, indicating acceptable reliability.

Table 4. Correlation Analysis of Business Strategies

\begin{tabular}{|c|c|c|c|c|c|c|c|c|c|}
\hline & Mean & $\begin{array}{l}\text { Std } \\
\text { Dev }\end{array}$ & Inn & Qual & CEff & Flex & Dep & MFoc & Tech \\
\hline Innovativeness & 2.81 & 0.84 & 1 & $\begin{array}{c}0.193 \\
(*)\end{array}$ & $\begin{array}{c}0.228 \\
(* *)\end{array}$ & $\begin{array}{c}0.206 \\
(* *)\end{array}$ & $\begin{array}{c}0.178 \\
(*)\end{array}$ & $\begin{array}{c}0.373 \\
(* *)\end{array}$ & $\begin{array}{c}0.323 \\
(* *)\end{array}$ \\
\hline Quality & 4.68 & 0.43 & $(*)$ & 1 & $\begin{array}{c}0.551 \\
(*)\end{array}$ & $\begin{array}{c}0.240 \\
(* *)\end{array}$ & $\begin{array}{c}0.415 \\
(* *)\end{array}$ & 0.130 & $\begin{array}{c}0.222 \\
(* *)\end{array}$ \\
\hline $\begin{array}{l}\text { Cost } \\
\text { Efficiency }\end{array}$ & 4.40 & 0.51 & $(* *)$ & $(* *)$ & 1 & $\begin{array}{c}0.346 \\
(* *)\end{array}$ & $\begin{array}{c}0.457 \\
(* *)\end{array}$ & $\begin{array}{c}0.154 \\
(*)\end{array}$ & $\begin{array}{c}0.191 \\
(*)\end{array}$ \\
\hline Flexibility & 3.72 & 0.73 & $(* *)$ & $(* *)$ & $(* *)$ & 1 & $\begin{array}{c}0.517 \\
(* *)\end{array}$ & $\begin{array}{c}0.195 \\
(*)\end{array}$ & 0.091 \\
\hline $\begin{array}{l}\text { Depend } \\
\text { /Delivery }\end{array}$ & 4.36 & 0.57 & (*) & $(* *)$ & $(* *)$ & $(* *)$ & 1 & $\begin{array}{c}0.203 \\
(* *)\end{array}$ & 0.120 \\
\hline Market Focus & 3.67 & 0.82 & $(* *)$ & & (*) & $(*)$ & $(* *)$ & 1 & $\begin{array}{c}0.235 \\
(* *)\end{array}$ \\
\hline Tech. Dev. & 2.80 & 0.82 & $(* *)$ & $(* *)$ & (*) & & & $(* *)$ & 1 \\
\hline
\end{tabular}


The second stage involves correlation and regression analysis. The correlation analysis indicates a strong positive association between innovativeness and business strategy factors (Table 4). Significant one-to-one positive relationships of the aggregated factors are extracted from the correlation analysis. All business strategy factors correlate very significantly to innovativeness with $p<0.01$ except quality and dependability/delivery $(p<0.05)$. Therefore, we can generally deduce that the higher importance given to operations priorities, market focus and technology development are associated with increased innovative capabilities.

Table 5. Effects of Business Strategies on Innovativeness

\begin{tabular}{lcc}
\hline Independent Variables & Standard & $p$-Value \\
\hline Cost Efficiency & 0.115 & 0.190 \\
Quality & 0.051 & 0.547 \\
Depend/Delivery & -0.058 & 0.511 \\
Flexibility & 0.108 & 0.189 \\
Market Focus & 0.315 & 0.000 \\
Technology & 0.209 & 0.004 \\
\hline
\end{tabular}

This regression model is statistically very significant $(p<0.01)$ and the independent variables express $24.6 \%\left(R^{2}=0.246\right)$ of innovativeness. However, when business strategies have entered together to the multiple regression, only market focus $(\beta=0.315 ; p<0.01)$ and technology development $(\beta=0.209 ; p<0.01)$ have significant positive effects on innovativeness (Table 5). Thus, despite the fact that the model is significant, multiple regression analysis reveals only some business strategies have statistically significant effects over innovativeness. Moreover, correlation analysis already indicated all business strategy factors had significant one-to-one correlation to innovativeness. Hence, post hoc analysis reveals that market focus and technology development factors mediated the effects of cost efficiency, dependability/delivery, quality and flexibility factors on innovativeness.

In the third stage, based on the arguments above, a single-step Structural Equation Modeling (SEM) is performed to depict the relationship between business strategies and innovativeness with the simultaneous estimation of both measurement and structural models by AMOS v16 and analyzed according to goodness-of-fit indices. The resulting proposed paths of relations matching business strategies to innovativeness are presented in Figure 2. It summarizes the main findings of SEM analysis. The estimates on the arrows are regression weights and the estimates on the box corners are the squared multiple correlations. Each regression weight estimate in the model is statistically significant $(p<0.05)$. $23 \%$ of the innovativeness can be explained by that model. Market focus and cost efficiency have direct effects on innovativeness. 


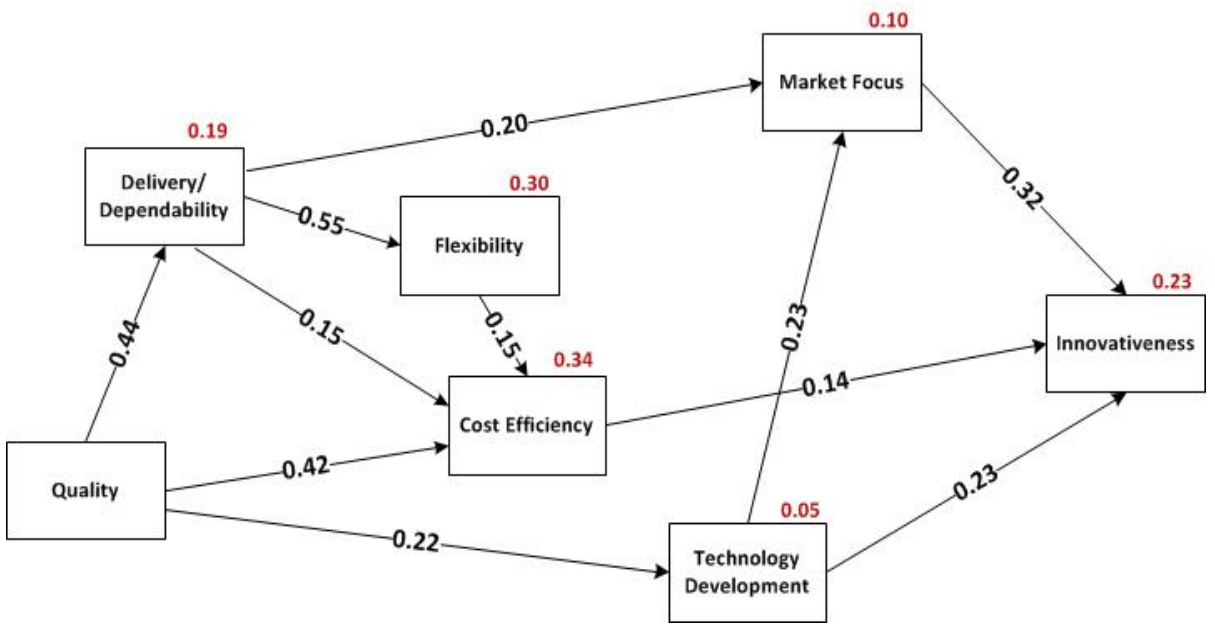

Fig. 2. Path analysis of business strategy components and innovativeness

\section{Conclusions}

In this paper, the hypothesis that there is a positive relationship between business strategy and innovativeness has been tested. The analysis is based on an empirical study conducted covering 184 manufacturing companies from the Northern Marmara region of Turkey. The findings summarized above expose the positive relationship between business strategy and innovativeness despite mediating effects between variables. Hence, the hypothesis put forward is supported.

The finding that market focus and technology development factors mediate the effects of operations priorities on innovativeness reveals the supporting role of operations priorities on these factors. That market focus, technology development and cost efficiency have direct effects on innovativeness is a further verification of this web of interactions of great managerial importance. But cost efficiency also depends on the manufacturing capabilities -quality, delivery/dependability, and flexibility. In order to be cost efficient, the firm has to manage all these capabilities in a complementary way rather than trading one against the other.

Acknowledgement. This research was supported by a grant from the Scientific and Technological Research Council of Turkey (TUBITAK) (SOBAG-105K105).

\section{References}

1. Akova, B., Ulusoy, G., Payzın, E., Kaylan, A.R.: New Product Development Capabilities of the Turkish Electronics Industry. In: 5th International Product Development Management Conference, Como, pp. 863-876 (1998)

2. Alpkan, L., Ceylan, A., Aytekin, M.: Performance impacts of operations strategies: a study on Turkish manufacturing firms. International Journal of Agile Manufacturing 6, 57-65 (2003) 
3. Boyer, K.K., Lewis, M.W.: Competitive priorities: Investigating the need for trade-offs in operations strategy. Production and Operations Management 11, 9-20 (2002)

4. Günday, G., Ulusoy, G., Kılıç, K., Alpkan, L.: Effects of innovation types on firm performance. International Journal of Production Economics 133, 662-676 (2011)

5. Hayes, R.H., Wheelwright, S.G.: Link manufacturing process and product life cycles. Harvard Business Review, 133-140 (January-February 1979)

6. Kathuria, R.: Competitive priorities and managerial performance: A taxonomy of small manufacturers. Journal of Operations Management 18, 627-641 (2000)

7. Khazanchi, S., Lewis, M.W., Boyer, K.K.: Innovation-supportive culture: The impact of organizational values on process innovation. Journal of Operations Management 25, 871884 (2007)

8. Leong, G., Snyder, D., Ward, P.T.: Research in process and content of manufacturing strategy. Omega 18, 109-122 (1990)

9. Metcalfe, J.S.: Evolutionary Economics and Creative Destruction. Routledge, London (1998)

10. Noble, M.A.: Manufacturing competitive priorities and productivity: An empirical study. International Journal of Operations \& Production Management 17, 85-99 (1997)

11. OECD: Oslo Manual: Proposed Guidelines for Collecting and Interpreting Technological Innovation Data. 3rd edn., Paris (2005)

12. Olson, E.M., Slater, S.F., Hult, G.T.M.: The performance implications of fit among business strategy, marketing organization structure, and strategic behavior. Journal of Marketing 69, 49-65 (2005)

13. Salavou, H.: The concept of innovativeness: Should we need to focus? European Journal of Innovation Management 7, 33-44 (2004)

14. Vickery, S.K., Droge, C., Markland, R.E.: Production competence and business strategy: Do they affect business performance? Decision Sciences 24, 435-455 (1993)

15. Ward, P.T., Mccreery, J.K., Ritzman, L.P., Sharma, D.: Competitive priorities in operations management. Decision Sciences 29, 1035-1046 (1998) 